\title{
STIMULANT LEVELS TO BE USED WITH TWO LOW INTENSITY HARVESTING (LIH) SYSTEMS OF RUBBER UNDER WET AND INTERMEDIATE ZONES OF SRI LANKA
}

\author{
W.R.A.C. Prasanna ${ }^{1}$, V.H.L.Rodrigo ${ }^{2}$, D.C. Abeysinghe ${ }^{1}$ and K. V. V. S. Kudaligama ${ }^{2}$ \\ ${ }^{\mathbf{1}}$ Department of Plantation Management, Faculty of Agriculture and Plantation Management, Wayamba \\ University of Sri Lanka, Sri Lanka \\ ${ }^{2}$ Rubber Research Institute of Sri Lanka, Agalawatta, Sri Lanka \\ Email: abeysinghedc@yahoo.com
}

\begin{abstract}
Low frequency harvesting (LFH) systems of rubber (Hevea brasiliensis) result in reduction in labour use and cost. However, yield stimulants (viz. Ethephon) are to be applied to enhance the yield in each harvest as a compromise for the yield reduction due to less number of harvesting days. A system of harvesting the tree once in four days $(\mathrm{S} / 2 \mathrm{~d} 4)$ has recently been introduced and a weekly harvesting system $(\mathrm{S} / 2 \mathrm{~d} 7)$ is presently under investigation. In $\mathrm{S} / 2 \mathrm{~d} 4$ and $\mathrm{S} / 2 \mathrm{~d} 7$, the required doze of Ethephon has exactly not known and that would vary with the climatic condition. Therefore, the present study was aimed to identify the suitable concentrations of Ethephon required for $\mathrm{S} / 2 \mathrm{~d} 4$ and $\mathrm{S} / 2 \mathrm{~d} 7$ systems under two climatic regions, wet and intermediate zones of Sri Lanka.
\end{abstract}

Ethephon was applied in four concentrations (i.e. 2\%, 3\%, 4\% and 5\%) and yield performance in each system was evaluated against that of the traditional harvesting systems of $\mathrm{S} / 2 \mathrm{~d} 2$ (tapping the tree once in two days). In the Intermediate zone, $\mathrm{S} / 2 \mathrm{~d} 4$ and $\mathrm{S} / 2 \mathrm{~d} 7$ systems showed a yield increase of 7 and 14 grams per harvest per $1 \%$ increase in Ethephon concentration, respectively. In the Wet zone, respective increases were recorded as 4 and 7 grams. The $\mathrm{S} / 2 \mathrm{~d} 4$ system required ca. $3.7 \%$ and $3.2 \%$ concentrations of Ethephon in the Intermediate and Wet zones, respectively, to achieve the yields given by $\mathrm{S} / 2 \mathrm{~d} 2$ system. In S/2 d7, 5\% Ethephon was sufficient for both zones. Ethephon concentrations tested had no adverse effects on tree health. Needs for commercial scale studies with financial analyses are discussed.

Keywords: Ethephon, Latex yield, Low Frequency Harvesting, Rubber, Stimulation

\section{INTRODUCTION}

Rubber, Hevea brasiliensis is commercially grown for its latex. In commercial rubber plantations, harvesting for latex (tapping) is the most costly operation contributing to $1 / 3$ of the cost of production (COP) (Rodrigo et al., 2004). In addition, it requires high level of skill which contributes to the shortage of latex harvesters. People are reluctant to join this profession, particularly from the younger generation due to poor wage structure and social dignity (Rodrigo et al., 2004). Harvesting of latex is undertaken through the systematic wounding in the bark of the trunk. In Sri Lanka, two harvesting systems are generally adopted in base panel tapping, i.e. half spiral cut tapped every other day $(\mathrm{S} / 2 \mathrm{~d} 2)$ and once in three days (S/2 d3). Recently, S/2 d4 system (i.e. half spiral cut tapped once in four days) has been introduced by the Rubber Research Institute of Sri Lanka (RRISL) (Rodrigo, 2009a) and also, the system of $\mathrm{S} / 2 \mathrm{~d} 7$ (i.e. tapping the tree in weekly intervals) is presently under investigation (Rodrigo, 2009b). Harvesting systems with the tapping frequencies less than once in two days are considered to be low frequency harvesting (LFH) systems (i.e. d3, d4 and d7 harvesting).

Studies revealed that $12 \%$ of rubber harvesters are generally absent every day and $37 \%$ of harvesters employed in the plantation sector are not skilled (Rodrigo et al., 2004). Removal of skill factor has neither been successful and nor cost effective in instances where it has been tried (eg. mechanized tapping); hence local and international focus has been made to improve 
the usage efficiency of skilled harvesters through the introduction of LFH systems (Nair et al., 2004). With increased time gap in LFH systems, each harvester can be allocated to a greater number of trees resulting in reduced worker requirement when compared with the traditional harvesting system. In order to compensate the yield drop associated with less number of harvesting days per tree, yield stimulants are applied (Rajagopal et al., 2004, Rodrigo et al., 2010). Ethephon (2-CEPA) is widely used as an effective yield stimulant in rubber plantations and commercially available in $2.5 \%$ or $5 \%$ formulations. These results in enhanced daily intake per harvester and therefore, wages of them can be increased and/or COP can be reduced. With less tappings, economical life of the tree increases providing an additional benefit to the growers (Rodrigo et al., 2010).

In $\mathrm{S} / 2 \mathrm{~d} 4$ and $\mathrm{S} / 2 \mathrm{~d} 7 \mathrm{LFH}$ systems, the suitable concentration of Ethephon is exactly not known and that would vary with the climatic condition. The objective of the present study was therefore to identify the suitable concentrations of Ethephon required for $S / 2 d 4$ and $S / 2 d 7$ systems under two climatic regions, Wet and Intermediate zones of Sri Lanka. In this exercise, it was expected to quantify the variation of yield parameters such as percentage dry rubber content in latex (\%DRC), average latex volume and yield per tree per tapping (GTT).

\section{MATERIALS AND METHODS}

\subsection{SITE DETAILS}

Experiment was set up in two locations, each from Wet and Intermediate zones of Sri Lanka. Notinghill estate in Kurunegala and Kuruwita estate of the RRISL represented the Intermediate Zone (IZ) and Wet Zone (WZ). Mature rubber fields with widely used Sri Lankan Hevea genotypes, i.e. RRIC 121 were selected for the study which was conducted during the period of April to June 2010. Trees were rain guarded to overcome rain interferences and harvested on BO-1 panel.

\subsection{EXPERIMENTAL LAYOUT AND ASSESSMENTS}

Proceedings of the $15^{\text {th }}$ International Forestry and Environment Symposium, 26-27 November 2010. 
Stimulation levels were applied on 10 tree plots which were replicated three times in both sites in a Randomized Complete Block Design within a harvesting system. Ethephon was applied on trees tapped with $\mathrm{S} / 2 \mathrm{~d} 4$ and $\mathrm{S} / 2 \mathrm{~d} 7 \mathrm{LFH}$ systems at monthly and weekly intervals, respectively. Control plot tapped with $\mathrm{d} 2$ frequency was not stimulated and assessments were made on 3 replicate plots having 10 trees in each. All the trees were tapped by same harvester and sampling was done for one month period. Trees were tapped early in the morning and latex was collected carefully in each tree after the flow ceased. Latex of each replicate plot was bulked and measured for the volume. A sub sample of $50 \mathrm{ml}$ from each replicate was coagulated with $1 \%$ formic acid, milled and dried to get the exact dry rubber content of latex. Mean tree yield per harvest was estimated with the knowledge of latex volume and dry rubber content in latex and the number of trees tapped in each replicate plot.

\subsection{DATA ANALYSIS}

Data analyses were made using the statistical package Minitab version 14. One way ANOVA was performed to assess the overall significance in stimulation levels whilst mean separation was done with Turkey. Effect of Ethephon concentration on latex yield was separately assessed with the simple linear regression in Excel (MS office).

\section{RESULTS AND DISCUSSION}

In Intermediate zone (IZ), \%DRC tended to increase with the reduction in tapping frequency with that the highest \%DRC was recorded in S/2 d7 (Table 1). Nevertheless in Wet zone (WZ), the highest \%DRC was given by $\mathrm{S} / 2 \mathrm{~d} 4$ and \%DRC values of $\mathrm{S} / 2 \mathrm{~d} 2$ and $\mathrm{S} / 2 \mathrm{~d} 7$ were quite comparable (Table 2). Within a particular LFH system, Ethephon concentration had no significant effect on \%DRC in both climatic zones. Although \%DRC in S/2 d7 was recorded as the lowest and significantly different $(\mathrm{p}<0.05)$ from the value of $\% \mathrm{DRC}$ at $2 \%$ Ethephon, it was above $30 \%$ which is considered to be the critical level in latex harvesting. Therefore, stimulation levels tested in the present study had no adverse effects on tree health through the over synthesis of latex.

Table 1: Percentage Dry Rubber Content (\%DRC) and latex volume per tree per tapping in different harvesting systems in the Intermediate Zone

\begin{tabular}{llllllllll}
\hline & $\mathrm{S} / 2$ & $\mathrm{~S} / 2 \mathrm{~d} 4$ & & \multicolumn{7}{c}{$\mathrm{S} / 2 \mathrm{~d} 7$} \\
\cline { 2 - 9 } & $\mathrm{d} 2$ & $\mathbf{E C 2 \%}$ & $\mathbf{E C 3 \%}$ & $\mathbf{E C 4 \%}$ & $\mathbf{E C 5 \%}$ & $\mathbf{E C 2 \%}$ & $\mathbf{E C 3 \%}$ & $\mathbf{E C 4 \%}$ & $\mathbf{E C 5 \%}^{\mathrm{E}}$ \\
\%DRC & 31 & $38^{\mathrm{a}}$ & $37^{\mathrm{a}}$ & $38^{\mathrm{a}}$ & $37^{\mathrm{a}}$ & $40^{\mathrm{b}}$ & $40^{\mathrm{b}}$ & $39^{\mathrm{b}}$ & $40^{\mathrm{b}}$ \\
$\begin{array}{l}\text { Volume } \\
\text { (ml) }\end{array}$ & 110 & $145^{\mathrm{a}}$ & $177^{\mathrm{ab}}$ & $189^{\mathrm{b}}$ & $194^{\mathrm{b}}$ & $214^{\mathrm{c}}$ & $244^{\mathrm{cd}}$ & $291^{\mathrm{d}}$ & $306^{\mathrm{d}}$ \\
\hline
\end{tabular}

Harvesting systems $S / 2 d 2, S / 2 d 4$ and $S / 2 d 7$ refer to tapping the half of the circumference of the tree trunk once in two, four and seven days. $\mathrm{EC}=$ Ethephon concentration. Means followed by same letter in each row within a harvesting system are not significantly different at 0.05 levels.

Harvesting systems $\mathrm{S} / 2 \mathrm{~d} 2, \mathrm{~S} / 2 \mathrm{~d} 4$ and $\mathrm{S} / 2 \mathrm{~d} 7$ refer to tapping the half of the circumference of the tree trunk once in two, four and seven days. $\mathrm{EC}=$ Ethephon concentration. Means followed by same letter in each row within a harvesting system are not significantly different at 0.05 levels. 
Table 2: $\quad$ Percentage Dry Rubber Content (\%DRC) and latex volume per tree per tapping in different harvesting systems in the Wet Zone

\begin{tabular}{llllllllll}
\hline & $\mathrm{S} / 2$ & $\mathrm{~S} / 2 \mathrm{~d} 4$ & & \multicolumn{1}{c}{$\mathrm{S} / 2 \mathrm{~d} 7$} & & \\
\cline { 2 - 9 } & $\mathrm{d} 2$ & $\mathbf{E C 2 \%}$ & $\mathbf{E C 3 \%}$ & $\mathbf{E C 4 \%}$ & $\mathbf{E C 5 \%}$ & $\mathbf{E C 2 \%}$ & $\mathbf{E C 3 \%}$ & $\mathbf{E C 4 \%}$ & EC5\% \\
\%DRC & 34 & $39^{\mathrm{a}}$ & $40^{\mathrm{a}}$ & $38^{\mathrm{a}}$ & $37^{\mathrm{a}}$ & $38^{\mathrm{b}}$ & $36^{\mathrm{bc}}$ & $35^{\mathrm{bc}}$ & $35^{\mathrm{c}}$ \\
$\begin{array}{l}\text { Volume } \\
(\mathrm{ml})\end{array}$ & 92 & $132^{\mathrm{a}}$ & $104^{\mathrm{b}}$ & $129^{\mathrm{a}}$ & $139^{\mathrm{a}}$ & $258^{\mathrm{c}}$ & $283^{\mathrm{cd}}$ & $292^{\text {cd }}$ & $334^{\mathrm{d}}$ \\
\hline
\end{tabular}

In general, latex volume per tree per tapping increased with the decrease in harvesting frequency and with increase in Ethephon concentration in both climatic zones (Tables 1 and 2) despite a discrepancy in S/2 d4 system of $\mathrm{WZ}$ where latex volume in $2 \%$ Ethephon was higher than that of $3 \%$. Increase in latex volume with no compromise in $\%$ DRC further confirms the capability of rubber tree to synthesize more rubber with the increase in Ethephon concentration within the range tested. The reduction in harvesting frequency provides additional time for trees to generate more latex.

Therefore, for a given concentration of Ethephon, greater volume of latex is produced by $\mathrm{S} / 2 \mathrm{~d} 7$ harvesting system.

There was a clear linear relationship between the Ethephon concentration and the mean latex yield per tree per tapping (GTT) with all fitted equations explaining at or over $80 \%$ of the variability of data (Figures 1 and 2; Table 3). The yield response to a unit increase in Ethephon concentration was comparatively higher in $S / 2$ d7 than in $S / 2 d 4$ irrespective of the climatic zone. On average, $\mathrm{S} / 2 \mathrm{~d} 7$ provided 10.6 gram increase in GTT per $1 \%$ change in Ethephon concentration and that was ca. $85 \%$ higher than the rate increase in $S / 2$ d4. For any harvesting system, yield response was greater in IZ than in WZ. However, the intercepts of linear functions for IZ were quite less and therefore, higher concentrations of Ethephon were required to achieve comparable yields.

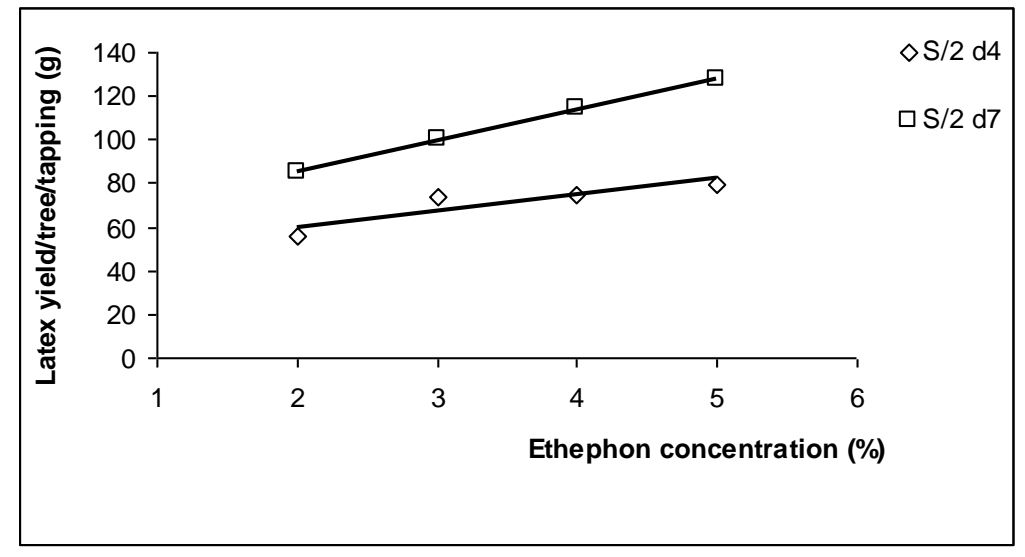

Figure 1: Response of latex yield to the concentration of Ethephon in the Intermediat zone

Harvesting systems $\mathrm{S} / 2 \mathrm{~d} 4$ and $\mathrm{S} / 2 \mathrm{~d} 7$ refer to tapping the half of the circumference of the tree trunk once in two, four and seven days. Equations for the fitted lines are given in Table 3. 


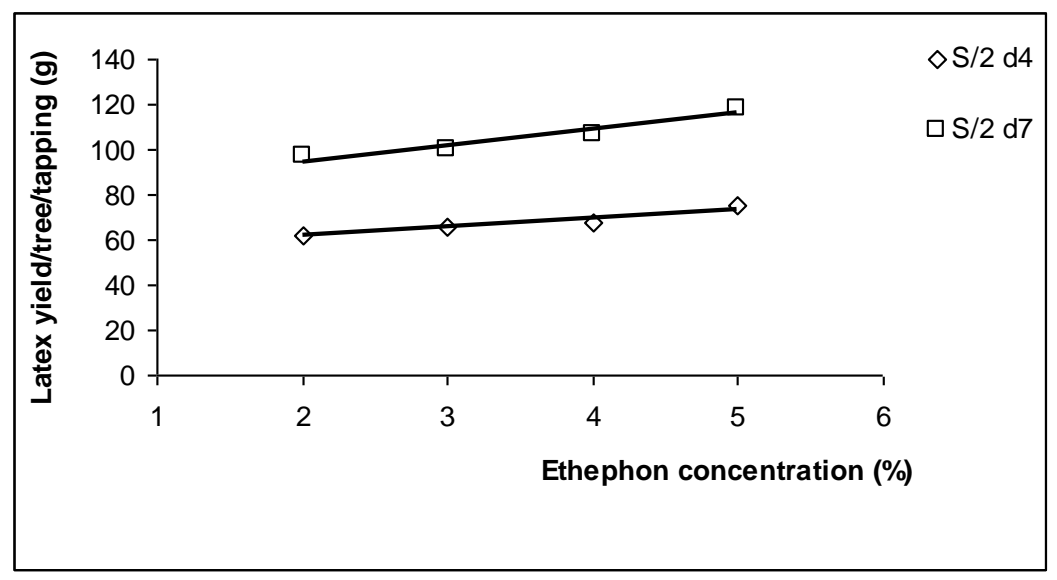

Figure 2: Response of latex yield to the concentration of Ethephon in the Wet zone

Harvesting systems $\mathrm{S} / 2 \mathrm{~d} 4$ and $\mathrm{S} / 2 \mathrm{~d} 7$ refer to tapping the half of the circumference of the tree trunk once in two, four and seven days. Equations for the fitted lines are given in Table 3.

Table 3: Summary of equations for the fitted lines in Figure 1 and 2

\begin{tabular}{lll}
\hline Ecological zone & Tapping system & Regression equation \\
\hline Intermediate zone & $\mathrm{S} / 2 \mathrm{~d} 4$ & $\mathrm{Y}=7.3809 \mathrm{X}+45.11$ \\
& $\mathrm{~S} / 2 \mathrm{~d} 7$ & $\mathrm{Y}=14.156 \mathrm{X}+57.252$ \\
Wet zone & $\mathrm{S} / 2 \mathrm{~d} 4$ & $\mathrm{Y}=4.011 \mathrm{X}+53.604$ \\
& $\mathrm{~S} / 2 \mathrm{~d} 7$ & $\mathrm{Y}=7.124 \mathrm{X}+80.511$ \\
\hline
\end{tabular}

Harvesting systems $\mathrm{S} / 2 \mathrm{~d} 4$ and $\mathrm{S} / 2 \mathrm{~d} 7$ refer to tapping the half of the circumference of the tree trunk once in two, four and seven days.

To be comparable with the overall yield given by the traditional harvesting system of $S / 2 \mathrm{~d} 2$ (i.e. $36.4 \mathrm{~g}$ per tree per month), it was required to obtain $72.8 \mathrm{~g}$ of GTT in S/2 d4 in IZ. According to the trend line fitted, this could be achieved with $3.74 \%$ concentration of Ethephon (Figure 1). In S/2 d7, 127.4 grams of GTT was expected in IZ and ca. $5 \%$ Ethephon could provide this amount (Fig. 1). Similarly, the expected levels of GTT in S/2 d4 and S/2 d7 were $66.6 \mathrm{~g}$ and $116.6 \mathrm{~g}$, respectively in WZ to obtain the overall yield given by $\mathrm{S} 2 / \mathrm{d} 2$ and the Ethephon concentrations of ca. $3.24 \%$ and $5 \%$ were required in this regard, respectively (Figure 2).

Despite of some fluctuations, GTT in S/2 d4 did not vary significantly among harvests after the stimulation in both IZ and WZ (Figures 3 and 4). Therefore, one month gap (frequency) kept for Ethephon stimulation in $\mathrm{S} / 2 \mathrm{~d} 4$ system appeared to be sufficient to maintain the latex yields continuously. In S/2 d7, there was a time bound increase in GTT in LFH systems with the repeated use in stimulants in IZ (Figure 5) whilst, no such effect was observed in WZ (Figure 6). No time bound decrease in yields in $S / 2 \mathrm{~d} 7$ in both climatic zones at any stimulation levels suggests that those stimulation levels used in the study were safer enough not to over exploit the tree. Therefore, sustainability has not been affected. 


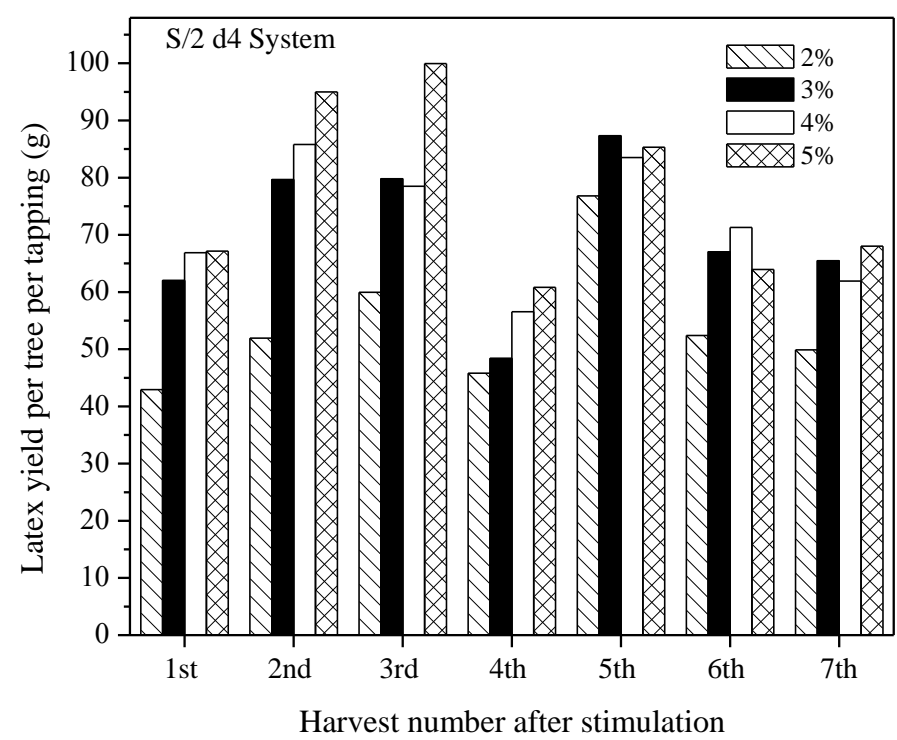

Figure 3: Yield response of the rubber tree in each harvest after stimulation in $S / 2 d 4$ harvestingsystem (i.e. harvesting the tree once in four days) in the Intermediate zone Different series represent the Ethephon concentration used for the stimulation

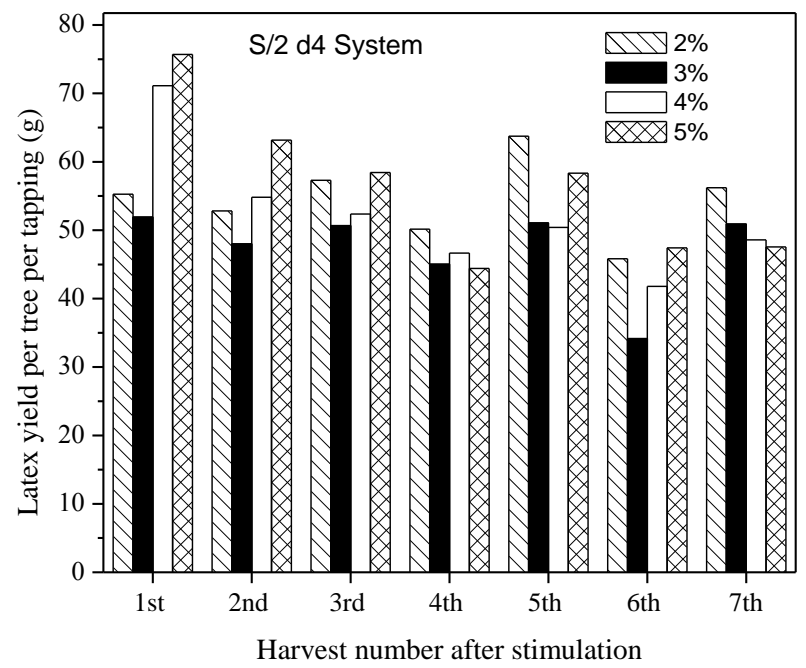

Figure 4: Yield response of the rubber tree in each harvest after stimulation in $S / 2 d 4$ harvesting system (i.e. harvesting the tree once in four days) in the Wet zone Different series represent the Ethephon concentration used for the stimulation

Nevertheless, the study assessed only the short-term impact of stimulation levels in LFH systems concerned (one month) and also with limited number of trees (10 trees in each). Therefore, Ethephon concentrations are to be repeated for a reasonable time period with few suitable concentrations to identify the best. Then, those should be applied in large scale to assess the overall productivity and practicality. In particular, impact on tapping panel dryness (TPD) is to be studied. Further, financial analysis is required with the cost on stimulation and yield output along with any recommendation. 


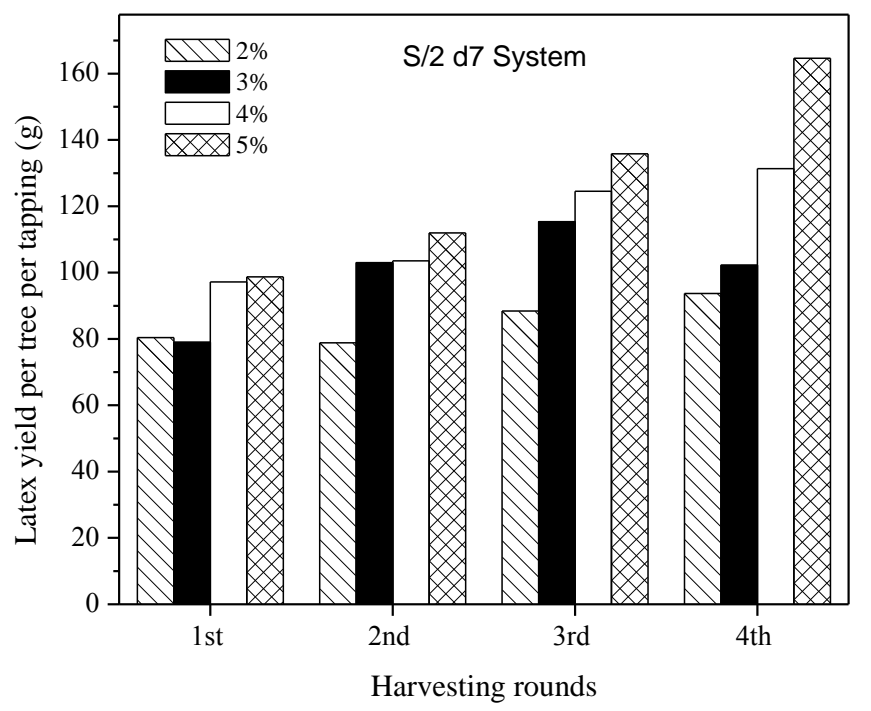

Figure 5: Yield response of the rubber tree in first four harvests with the commencement of $S / 2 d 7$ harvesting system (i.e. harvesting the tree once in seven days) in the Intermediate zone Different series represent the Ethephon concentration used for the stimulation

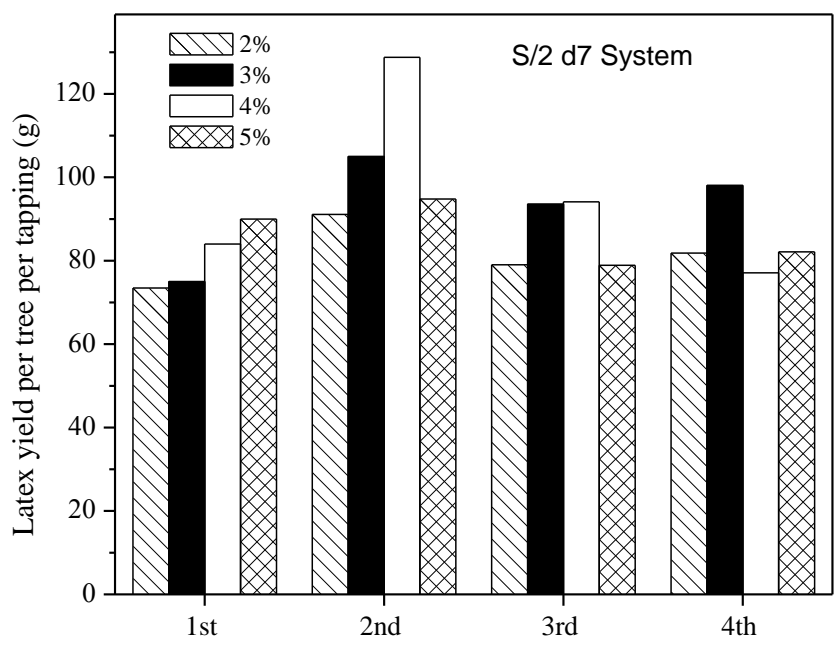

Harvesting rounds

Figure 6: Yield response of the rubber tree in first four harvests with the commencement of $\mathrm{S} / 2 \mathrm{~d} 7$ harvesting system (i.e. harvesting the tree once in seven days) in the Wet zone.

Different series represent the Ethephon concentration used for the stimulation

\section{CONCLUSION}

In conclusion, $\mathrm{S} / 2 \mathrm{~d} 4$ system requires $3.7 \%$ and $3.2 \%$ concentrations of Ethephon in the Intermediate and Wet Zones, respectively, to achieve the yields given by $\mathrm{S} / 2 \mathrm{~d} 2$ system. For $\mathrm{S} / 2 \mathrm{~d} 7$, Ethephon concentration of $5 \%$ appeared to suitable for both zones. The study also revealed that the range tested in Ethephon concentrations had no adverse effect on tree health.

Proceedings of the $15^{\text {th }}$ International Forestry and Environment Symposium, 26-27 November 2010.

Published by Department of Forestry and Environmental Science, University of Sri Jayewardenepura, Sri Lanka. 
However, long-term studies at commercial scale are required before coming to firm conclusions.

\section{REFERENCES}

Nair, U., Nair, R., Thomas, B.M., Gopalakrishnan, J., 2004. Latex Diagnosis in relation to Exploitation Systems in Clone RRII 105. Journal of Rubber Research. 7 (2), 127-137.

Rajagopal, R., Vijayakumar, K.R., Thomas, K.U., Karunaichamy, K., 2004. Effect of Judicious Ethephon Application on Yield Response of Hevea brasiliensis (clone RRII 105) under 112S d $136 \mathrm{~d} 17$ tapping system. Journal of Rubber Research. 7 (2), 138-147.

Rodrigo, V.H.L., Wickramarathna, N.A.A.D., Vidanapathirana, R.D., 2004. Productivity and tapper shortage in rubber plantations; Low frequency tapping can address the shortage of tappers in rubber plantations of Sri Lanka. In: Proceedings of the First Symposium on Plantation Crop Research, Colombo, Sri Lanka July 8-9 2004. 32- 42.

Rodrigo, V.H.L., 2009a. Exploitation methods to sustain high performance under changing scenarios. In: Proceedings of the Centennial Rubber Conference. Colombo, Sri Lanka, 12-13 May 2009. 29-31.

Rodrigo, V.H.L., 2009b. Annual Review- 2009, Rubber Research institute of Sri Lanka, Agalawatte. 89-99.

Rodrigo, V.H.L., Kudaligama, K.V.V.S., Randunu, R.P.S. and Hewamanage, D.S., 2010. Commercial application of low frequency harvesting systems in the Intermediate zone of Sri Lanka. In: Proceedings of the Third Symposium on Plantation Crop Research, Colombo, Sri Lanka 30, September - 01, October, 2010. 100- 107. 